\title{
Fatal giant cell myocarditis after thymoma resection in myasthenia gravis
}

Thomas M. Joudinaud, MD, PhD, Elie Fadel, MD, PhD, Vincent Thomas-de-Montpreville, MD, Sacha Mussot, MD, Erwan M. Flecher, MD, and Phillippe G. Dartevelle, MD, Le Plessis Robinson, France

$\mathrm{M}$ yasthenia gravis (MG) results in weakness and fatigability of skeletal muscles caused by an autoimmune-antibody reaction against acetylcholine receptors at the neuromuscular junction. Treatment includes anticholinesterase agents, thymectomy, and immunosuppression. Surgical thymectomy can induce remission or improvement, allowing for reduction in immunosuppressive treatment. ${ }^{1}$ Although myocardial dysfunction is usually minimal in MG, thymoma can be associated with severe myocardial failure. ${ }^{2} \mathrm{We}$ report a rare case of fatal giant cell myocarditis (GCM) after a thymoma resection in $\mathrm{MG}$.

\section{Clinical Summary}

A 43-year-old man with no previous medical history was given a diagnosis of MG. Thoracic computed tomographic scanning revealed an anterior mediastinal tumor without superior vena caval invasion on venography. Complete resection was performed through a median sternotomy with resection of the anterior pericardium, sparing both phrenic nerves. Histologic analysis revealed an encapsulated thymoma extending in mediastinal fat. The patient was discharged on day 5 after an uneventful recovery. One week later, after a short episode of fever and diarrhea, the patient was referred for severe dyspnea associated with hypoxia. Physical examination showed an irregular tachycardia at 120 beats/min. Electrocardiography showed diffuse low voltages and atrial fibrillation. Transthoracic echocardiography showed global hypokinesis of both dilated ventricles. Coronary and pulmonary angiograms ruled out myocardial infarction and massive pulmonary embolism. Because of rapid hemodynamic deterioration, the patient was intubated and ventilated, and inotropic support was administered. Despite maximal medical treatment, the patient experienced cardiogenic shock and was placed on circulatory support (extracorporeal membrane oxygenation), and a myocardial biopsy was performed through the reopened sternotomy. The patient died from severe multiorgan failure 18 hours later. The biopsy showed diffuse myocardial necrosis with infiltration by lymphocytes, histio-

\footnotetext{
From the Department of Thoracic and Vascular Surgery and Heart-Lung Transplantation, Hôpital Marie Lannelongue, Le Plessis-Robinson, France.

Received for publication Sept 4, 2005; accepted for publication Sept 28, 2005 .

Address for reprints: Elie Fadel, MD, Laboratoire de Chirurgie Expérimentale, Hôpital Marie-Lannelongue, 133 avenue de la Résistance, 92350 Le Plessis-Robinson, France (E-mail: efadel@free.fr).

J Thorac Cardiovasc Surg 2006;131:496-7

$0022-5223 / \$ 32.00$

Copyright (C) 2006 by The American Association for Thoracic Surgery

doi:10.1016/j.jtcvs.2005.09.035
}

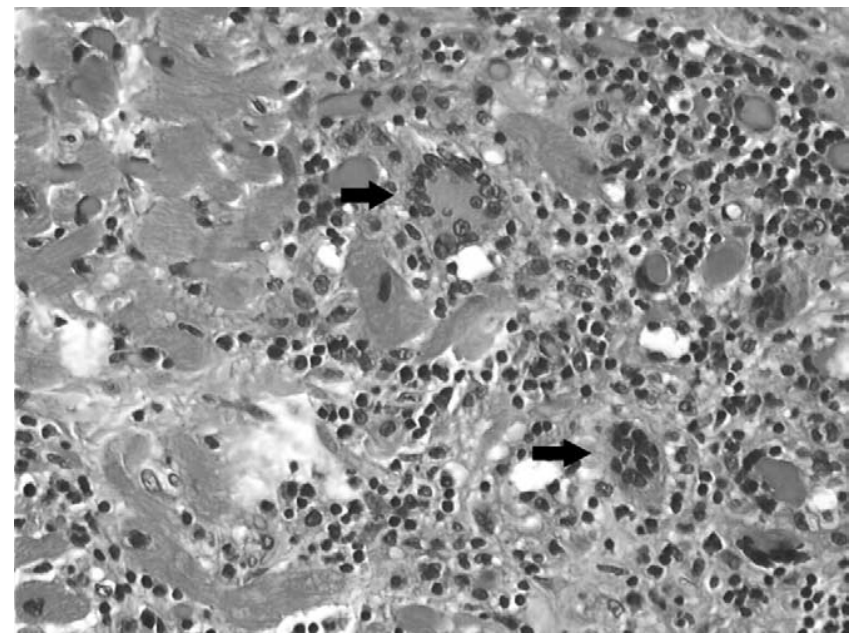

Figure 1. Histologic aspect of giant cell myocarditis obtained by means of surgical biopsy. Myocytes appear degenerative. The cellular infiltrate contains lymphocytes, histiocytes, and multinucleated giant cells (arrows). (Hematoxylin and eosin stain, original magnification $400 \times$.)

cytes, and giant multinucleated cells (Figure 1) characteristic of GCM. Immunohistochemistry showed that lymphocytes were mostly $\mathrm{CD}^{+} \mathrm{T}$ cells and that histiocytes and giant cells were $\mathrm{CD}^{+} 8^{+}$.

\section{Discussion}

Idiopathic GCM is a rare and usually fatal disease that affects middle-aged men and women. Rapid progressive heart failure in weeks or months associated with ventricular arrhythmia characterizes the clinical course. Diagnosis is made on histology of the myocardium obtained from myocardial biopsy or explanted heart. ${ }^{2,3}$ We report the second case of GCM occurring after thymoma resection. Glennon and colleagues ${ }^{2}$ reported a patient who had fatal cardiogenic shock with ventricular tachycardia resistant to medical treatment 10 days after a thymoma resection. Postmortem histology confirmed GCM. In both cases the severe course of the fatal heart failure developed over a period of a few hours. In contrast to our report, Glennon and colleagues did not describe any autoimmune disorder in their patient. Although the majority of GCM reported by Cooper and associates ${ }^{3}$ occurred in apparently healthy persons, an association between GCM, thymoma, and/or MG or other autoimmune disorders has been described in numerous case reports over the last 50 years. ${ }^{2,3}$ MG is the most common parathymic syndrome (approximately $45 \%$ of patients having a 
thymoma), and $10 \%$ to $15 \%$ of patients with MG are found to have a thymoma. ${ }^{1}$ An autoimmune mechanism dependant on $\mathrm{CD}^{+}{ }^{+} \mathrm{T}$ lymphocytes is suspected to be responsible for the GCM, and immunosuppressive therapy has been used to delay transplantation. ${ }^{3}$ Median survival or time to heart transplantation of 5 to 6 months had been reported in GCM. ${ }^{3}$ Ventricular assistance as a bridge to heart transplantation was reported in patients who had terminal heart failure within a week. ${ }^{4}$ Our patient, like the one reported by Glennon and colleagues, ${ }^{2}$ presented in shock within hours after the onset of symptoms, despite maximal medical treatment. Both patients had no sign of active myocarditis before the thymoma resection, and the operation might have in some way triggered the disease. This very aggressive form of the disease after a thymoma resection did not allow a premortem diagnosis and thus the administration of appropriate immunotherapy or a ventricular support device as a bridge to heart transplantation. ${ }^{3,4}$ Transplantation remains the treatment of choice in the absence of recovery of myocardial function with immunosuppressive agents, although the disease is known to recur in the transplanted heart. ${ }^{3}$ Marelli and coworkers ${ }^{4}$ reported one case of recovery of myocardial function with biventricular assistance for 10 days and immunosuppressive therapy with a follow-up of 3 years. Even if GCM appears to be a very rare disease, this diagnosis should be considered in patients who experience rapidly progressive heart failure after thymoma resection. Although the possibility of massive pulmonary embolism or myocardial infarction should not be ignored, early myocardial biopsy might lead to the diagnosis. Appropriate immunosuppressive therapy and circulatory support as a bridge to transplantation can be administrated.

\section{References}

1. Drachman DB. Myasthenia gravis. N Engl J Med. 1994;330:1797-810.

2. Glennon PE, Petersen ME, Sheppard MN. Fatal giant cell myocarditis after resection of thymoma. Heart. 1996;75:531-2.

3. Cooper LT, Berry GJ, Shabetai R. Idiopathic giant cell myocarditisnatural history and treatment. Multicenter Giant Cell Myocarditis Study Group Investigators. N Engl J Med.1997;336:1860-6.

4. Marelli D, Kermani R, Bresson J, Fishbein MC, Hamilton M, Moriguchi J, et al. Support with the BVS 5000 assist device during treatment of acute giant-cell myocarditis. Tex Heart Inst J. 2003;30:50-6.

\section{Using Surgicel to buttress the staple line in lung volume reduction surgery for chronic obstructive pulmonary disease}

Jang-Ming Lee, MD, PhD, Jen-Deh Pan, MD, Wei-Cheng Lin, MD, and Yung-Chie Lee, MD, PhD, Taipei, Taiwan

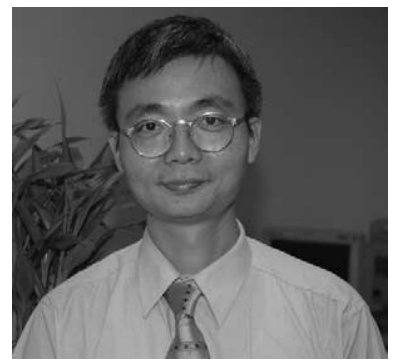

Dr W. Lee
A lthough effective for palliating the symptoms of chronic obstructive pulmonary disease (COPD), lung volume reduction surgery for COPD is highly vulnerable to postoperative major or persistent air leakage. ${ }^{1}$ Staple line reinforcement has been developed to prevent this complication, including using polyglycolic acid, ${ }^{2}$ bovine pericardial strips, ${ }^{3}$ or autologous parietal pleura. ${ }^{4}$ These materials either carry a high $\operatorname{cost}^{2,3}$ or take a substantial amount of time for preparation. ${ }^{4} \mathrm{~A}$ low-cost and easily available material for staple

\footnotetext{
From the Department of Surgery, National Taiwan University Hospital, Taipei, Taiwan.

Received for publication Aug 2, 2005; accepted for publication Sept 9, 2005.

Address for reprints: Yung-Chie Lee, MD, PhD, Department of Surgery, National Taiwan University Hospital, Taipei, Taiwan, Republic of China. 7, Chung-Shang South Rd, Taipei, Taiwan (Email: wuj@ha.mc.ntu.edu.tw).

J Thorac Cardiovasc Surg 2006;131:497-8

$0022-5223 / \$ 32.00$

Copyright $\odot 2006$ by The American Association for Thoracic Surgery

doi:10.1016/j.jtcvs.2005.09.039
}

buttressing is needed to facilitate its clinical application. We report a new technique using oxidized regenerated cellulose (Surgicel, Johnson \& Johnson) for lung volume reduction surgery for COPD.

\section{Clinical Summary}

Patient 1. A 72-year-old man with COPD complained of progressive exertional dyspnea unresponsive to bronchodilator treatment. He had left pneumothorax and received a thoracoscopic wedge resection on the pulmonary left upper lobe 4 years ago. Chest computed tomography revealed diffuse emphysematous change of the bilateral lung, especially in the right middle lobe. For intractable dyspnea, video-assisted thoracic surgery for lung volume reduction surgery on the right lung was arranged. About $30 \%$ of the pulmonary right upper lobe at the apex and 50\% of the right middle lobe at the basal portion was resected with a continuous staple line (Figure 1, B, C, and D). Before the lung resection, a strip of Surgicel, $4 \times 8 \mathrm{~cm}$, was tied on each site of the staple (Figure 1, $A$ ). The working port on the anterior axillary line of the fourth intercostal space was enlarged to $3 \mathrm{~cm}$ to prevent dislocation of fixed Surgicel during staple introduction. A total of 7 sets of Endo-GIA, $60 \times 4.8 \mathrm{~mm}$, and 2 sets of Endo-GIA, $45 \times 4.8$ $\mathrm{mm}$, staples (Tyco Health Care, US Surgical) were used during the operation. It took 2 hours for the entire surgical procedure. The 